\title{
Characteristics of Heat Transfer for Heat Pipe and Its Correlation
}

\author{
Aloke Kumar Mozumder, Mohammed Shafiul Hasib Chowdhury, and Abul Fahad Akon
}

Department of Mechanical Engineering, Bangladesh University of Engineering and Technology, Dhaka1000, Bangladesh

Correspondence should be addressed to Aloke Kumar Mozumder, aloke@me.buet.ac.bd

Received 27 January 2011; Accepted 20 March 2011

Academic Editors: W.-H. Chen and J. Clayton

Copyright ( 2011 Aloke Kumar Mozumder et al. This is an open access article distributed under the Creative Commons Attribution License, which permits unrestricted use, distribution, and reproduction in any medium, provided the original work is properly cited.

In spite of wide application of heat pipe in microelectronics cooling system, a complete understanding of heat pipe mechanism has not yet been completed. An experimental investigation of heat transfer performance of a heat pipe for dry condition and with three different liquids as acetone, methanol, and water having four fill ratios, for each liquid has been conducted in the present study. The heat pipe was $5 \mathrm{~mm}$ in diameter and $150 \mathrm{~mm}$ long with a thermal capacity of $10 \mathrm{~W}$. The evaporator and condenser's temperatures were measured with varying input power to estimate the heat transfer coefficient. This study reveals that the dominating parameters for the heat transfer coefficient are evaporator surface temperature, saturated boiling temperature of working fluid, latent heat of vaporization, and fill ratio. The investigation also shows that $85 \%$ fill ratio can be regarded as an optimum value for a heat pipe. A new correlation for the heat transfer coefficient has been proposed here which fairly agrees with the experimental results.

\section{Introduction}

The life time of an integrated circuit (IC) used in electronic devices depends on its operating temperature creating a trade-off situation either to enlarge the package to accept additional cooling or to sacrifice IC lifetime. This is a great challenge in thermal design management. The solution is miniaturization of cooling technique. Among other cooling techniques, heat pipes emerged as the most appropriate technology and cost effective thermal design solution due to its excellent heat transfer capability, high efficiency, and structural simplicity. Because of the phase change characteristic, heat pipes have a tremendous capacity for transferring heat, they are often referred to as the "superconductors" of heat. Today heat pipes are widely used in computer, telecommunication, and other various electronics equipment.

The heat pipe consists of a hollow tube closed at both ends and partially filled with a liquid that boils at a desired temperature. One end of the tube is immersed in the warm region and the other end in the cold region. The objective is to transfer heat through the pipe from warmer to the colder region. Due to space constraints in most of personal computers and telecommunication systems placed constraints on the size of heat pipes, normally miniature heat pipes (MHP) of diameter 3 to 6 millimeter and less than 400 millimeters, are preferred. The MHP applications for cooling telecom boots and notebook computers were started in the last decade, and now $80 \%$ of notebook PCs are using MHP. The study of heat pipes, started more than a century before. Due to increasing demand of applications of heat pipes many researchers [1-5] investigated the characteristics of heat pipe both experimentally and analytically.

A steady-state mathematical model of a loop heat pipe was established and compared with experimental results by Bai et al. [6]. The model was able to predict the decreasing length of the condenser two-phase zone under the constant conductance mode caused by the volume expansion of the liquid in the compensation chamber, and was in good agreement with the experimental data. A series of tests have been carried out by Chen et al. [7] with a miniature loop heat pipe (mLHP), which was developed for consumer electronics cooling with four horizontal and four vertical orientations under different sink temperatures. The mLHP was a cylindrical evaporator of $5 \mathrm{~mm}$ outer diameter and $29 \mathrm{~mm}$ length. The steady-state operating characteristics were similar for different orientations except for the orientation where the evaporator was above the compensation chamber. At an evaporator temperature of $75^{\circ} \mathrm{C}$, an evaporator heat load up 
to $70 \mathrm{~W}$ could be reached with thermal resistance of about $0.2^{\circ} \mathrm{C} / \mathrm{W}$. The transient behavior of the $\mathrm{mLHP}$ was studied in detail.

The research on a novel miniaturized loop heat pipe (LHP) consisted of an evaporator, a condenser, vapor, and liquid lines was presented by Tang et al. [8]. In the LHP, the evaporator was separated into two parts of boiling and suction chambers by a vapor separator, which drove vapor to one-way flow to vapor line. Moreover, the bottom of evaporator was connected as the cycle channel of refrigerant.

A thorough experimental investigation was carried out by $\mathrm{Li}$ et al. [9] on a copper-water compact loop heat pipe (LHP) with a unique flat, square evaporator with dimensions of $30 \mathrm{~mm}(L) \times 30 \mathrm{~mm}(W) \times 15 \mathrm{~mm}(H)$ and a connecting tube having an inner diameter of $5 \mathrm{~mm}$. Using a carefully designed experimental system, the startup process of the LHP when subjected to different heat loads was studied and the possible mechanisms behind the observed phenomena were explored.

The characteristics of counter-flow heat exchanger units, using heat pipes or two-phase closed thermosyphon as the heat-transfer element, are studied experimentally, and a simple analytical model was developed to predict the performance of such units using thermosyphon by Lee and Bedrossian [10]. The maximum heat-transfer rate has a unique functional relationship between the ratio of two stream mass flow rates, and the ratio of heated to cooled lengths of the heat-transfer elements, regardless of element bundle geometries. A heat-transfer analysis of an inclined two-phase closed thermosyphon was developed by Zuo and Gunnerson [11]. The inclination-induced circumferential flow was unfavorable with respect to dry out because the thin top-side liquid film was easier to boil off but contrastingly was favorable with respect to flooding because the thick underside film corresponded to a large gravity force.

A mathematical model and its numeric solution for the laminar two-phase flow of liquid and vapor of working fluid in the capillary structure of micro heat pipes were investigated by Garcia et al. [12]. The mathematical model is formulated for steady state, one-dimensional flow for the vapor and quasione-dimensional flow for the liquid. The reported results are the longitudinal distributions of the mass flow rate, the pressure and the traverse section area of the phases, and the curvature radius of the liquid-vapor interface, for a micro heat pipe with capillary structure of cross-section form of four tips astroid. The relation between the maximum heat transfer capacity and the capillary pressure is analyzed. To verify the mathematical models, the results obtained are compared with data reported in the specialized literature.

Based on the momentum conservation and LaplaceYoung equations, an analytical expression for the minimum meniscus radius was derived and an expression for the maximum capillary heat transport limit in micro/small heat pipes was obtained by $\mathrm{Ma}$ and Peterson [13]. These expressions incorporated the shear stresses at the liquid/solid and liquid/vapor interfaces, contact angle effects, vapor pressure drop, tilt angle, groove dimensions, and channel angle effects. A detailed mathematical model for predicting the heat transport capability and temperature gradients that contribute to the overall axial temperature drop as a function of heat transfer in a micro heat pipe has been also developed by Peterson and $\mathrm{Ma}[14]$.

The objectives of the present study includes finding dominating parameters of heat transfer of a heat pipe. An experimental investigation of heat transfer performance of the heat pipe for dry condition and with three different liquids as acetone, methanol, and water having four fill ratio for each liquid has been conducted in the present study. The ultimate goal of this investigation is to build a new correlation of heat transfer coefficient with the dominating parameters.

\section{Experiment}

The length of the copper tube heat pipe was $150 \mathrm{~mm}$, and it has $5 \mathrm{~mm}$ inner diameter and $8 \mathrm{~mm}$ outer diameter (as shown in Figure 1). Ni-Cr wire having inner diameter $8 \mathrm{~mm}$ and length $50 \mathrm{~mm}$ was used to make a heater of $230 \mathrm{~V}, 50 \mathrm{~W}$ capacity, and the heater was used for providing the required heat source at the evaporator. The evaporator and adiabatic sections of the heat pipe are insulated using asbestos to minimize the heat loss through these portions. A variac was used to control the heat input. K-Type thermocouple wires were used as temperature sensors (thermocouples' positions are shown with black solid dot in the Figure 1 with their measurements). An 8-channel digital temperature indicator is used to measure the temperature. Five copper fins of length $50 \mathrm{~mm}$, width $15 \mathrm{~mm}$, and thickness $0.5 \mathrm{~mm}$ were brazed on the condenser end. Experiments were conducted with dry run (i.e., without working fluid in the tube) and wet run (with working fluid inside). The heat pipe without working fluid essentially. represents metallic conductor. Its performance is considered as the base for the evaluation of heat pipe (i.e., with working fluid in it). The temperature rise by using the heater was observed at regular intervals till the steady state is achieved. Experiments were repeated for different heat inputs with different fill ratios and various plots were drawn to study the performance of miniature heat pipe to optimize the fluid inventory.

2.1. Experimental Procedure. The test section consists of three parts, as mentioned earlier, evaporator, adiabatic, and condenser section. In the experiment, the heat transfer parameters were measured for three different liquids (distilled water, methanol, and acetone). Also, the parameters were measured for dry run condition (without any liquid). So, two miniature heat pipes were fabricated. For dry run condition, the heat pipe was sealed at bottom and top. In the case of the heat pipe where liquids were used, the bottom was sealed and top was sealed by a cork. Ni-Cr thermic wire was wound round the evaporator section. Power to the heater was provided from line supply through a variac. Fins were attached at the condenser section and a fan was directed towards the fins for forced convection to occur at this section.

Six sets of thermocouple wires were fixed with the body by means of thermal resisting glue. At first each thermocouple sets, were fused together at the top point, 


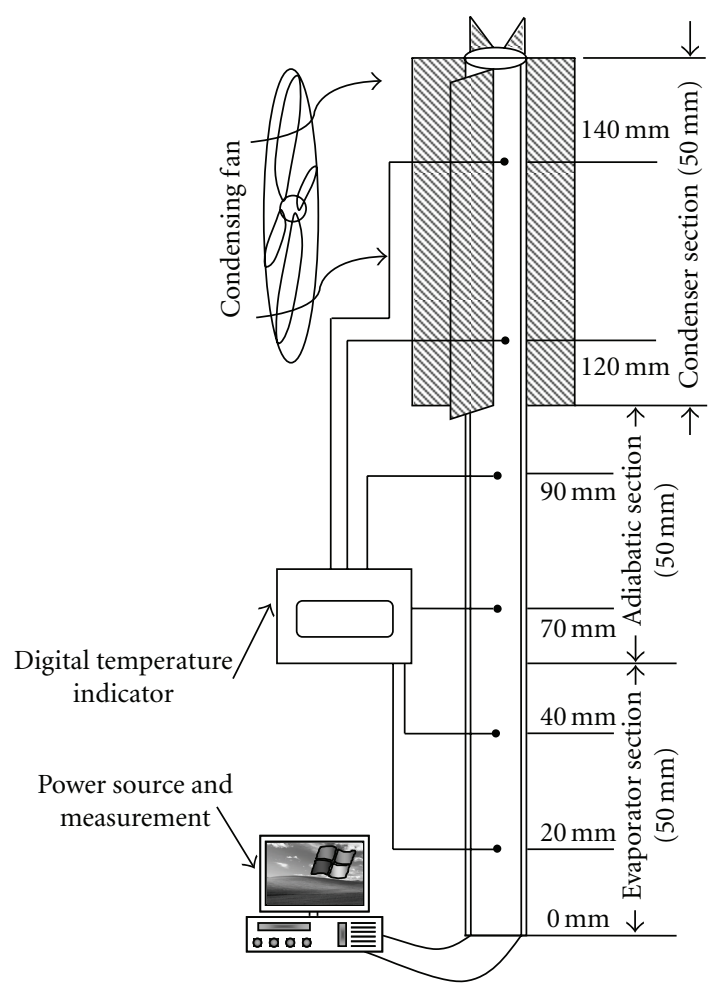

FIGURE 1: Schematic diagram of experimental setup.

and it was ensured that except the top point, they do not touch at any other points. Then they were attached with the body. The other ends of the thermocouple wires were connected with the digital thermocouple reader by means of connecting wires. Thermocouples were placed at six points on the surface of the heat pipe, two at evaporator section, two at adiabatic sections, and two at condenser section. Thermocouples at each section were placed at an interval of $20 \mathrm{~mm}$ and for some cases $30 \mathrm{~mm}$ as shown in the Figure 1.

Experiments were conducted with dry run (without any working fluid in the tube) and wet run (with working fluid inside). The heat pipe without working fluid essentially represents metallic conductor. Its performance is considered as the base for the evaluation of the heat pipe (with working fluid in it). The transient tests were conducted on the heat pipe, in which heater was put on and the temperature rise was observed at regular intervals till the steady state, was achieved. After achievement of steady state the temperatures at the six points were noted by changing the positions of the selector switch. This experiment was repeated for different heat inputs, different fill ratios, and for different working fluids. Various plots were drawn to study the performance of the miniature heat pipe to optimize the fluid inventory. The different heat inputs were achieved by changing the output voltage from the variac.

Fill ratio means the percentage of the evaporator section volume that is filled by the working fluids. The fill ratios used in this experiment were $35 \%, 55 \%, 85 \%$, and $100 \%$ of the evaporator volume for all three different working fluids.
All the temperature readings, at the six points on the heat pipe surface, were taken for all the three working fluids and for all the fill ratios after reaching steady-state condition.

2.2. Data Reduction. Effectiveness of a heat pipe can be represented by a system of thermal resistance. The thermal resistance $R$ can be represented by

$$
R=\frac{T_{e}-T_{c}}{Q}{ }^{\circ} \mathrm{C} / \mathrm{W} .
$$

The overall heat transfer coefficient, $h$ of the heat pipe can be given by

$$
h=\frac{Q}{A\left(T_{e}-T_{c}\right)} \mathrm{W} / \mathrm{m}^{2} \cdot{ }^{\circ} \mathrm{C} .
$$

Here, $T_{c}$ is the average temperature at the condenser $\left({ }^{\circ} \mathrm{C}\right), T_{e}$ is the average temperature at the evaporator $\left({ }^{\circ} \mathrm{C}\right), Q$ is the heat input $(\mathrm{W})$, and $A$ is the heat transfer surface area at the evaporator $\left(\mathrm{m}^{2}\right)$.

\section{Results and Discussions}

The experiment was conducted both with working fluid and without fluid. Without working fluid, the situation is called dry mode, and with working fluid the situation is called wet mode. The dry mode experiment represents the heat transfer characteristics in an ordinary conductor, while the wet mode depicts the live heat pipe characteristics. Three different working fluids such as distilled water, methanol, and acetone which have varying useful working range of temperature are tested in this study. The heat pipe was filled with $35 \%, 55 \%, 85 \%$, and $100 \%$ of the evaporator volume tested for different heat input and working fluids.

3.1. Variation of Surface Temperature, $T_{s}$. Axial temperature profiles are drawn from the data of temperatures that is obtained at different axial distances on the heat pipe body. The axial temperature distribution along the heat pipe for dry run is shown in Figure 2. Actually, the figure represents the evaporator, adiabatic section, and condenser temperature variations with distance for dry run. The figure shows that the gradient of axial temperature distribution increases with heat input and shows larger temperature differences across the condenser and evaporator section. The trend is obvious since greater temperature slope is required for increased heat transfer in case of simple conduction heat transfer.

Wet run shows (as shown in Figure 3 ) reduced slopes of axial temperature distribution for acetone of $35 \%$ fill ratio at similar heat inputs, indicating the effective augmentation of heat transfer at even reduced temperature slopes. Similar trends are found for all other working fluids.

In case of acetone as working fluid, the slopes of axial temperature distribution are lower than those of water and methanol as shown in Figure 4. Up to the adiabatic section $(0-100 \mathrm{~mm})$, the surface temperature, $T_{s}$, for acetone is almost always higher than the $T_{\text {sat }}$ of acetone which means that it is higher than the saturated boiling temperature of 

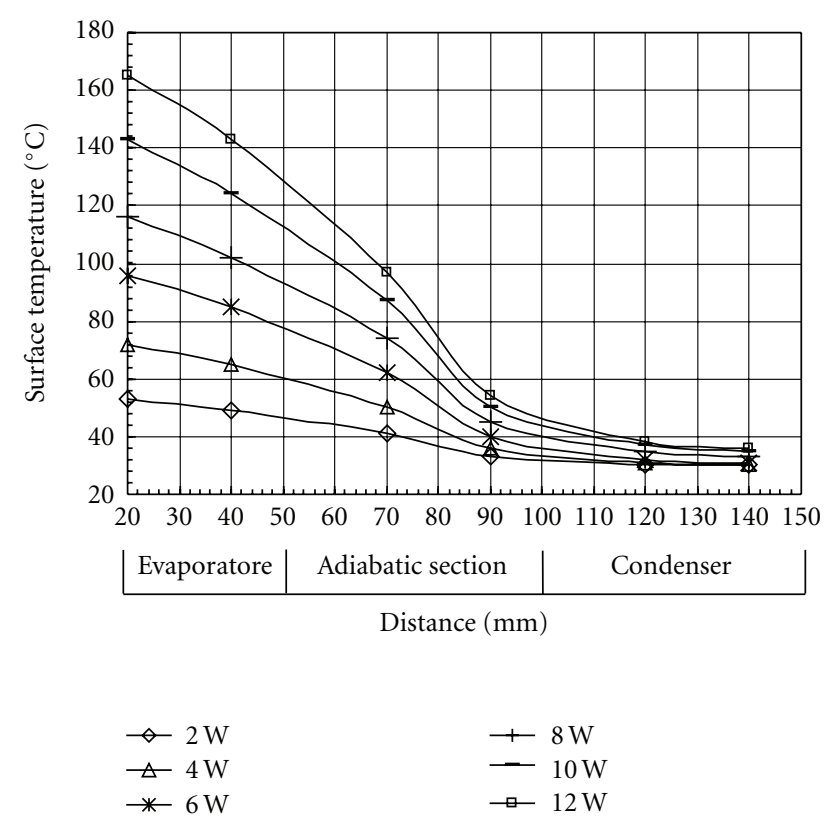

Figure 2: Temperature distribution in axial direction for dry run.

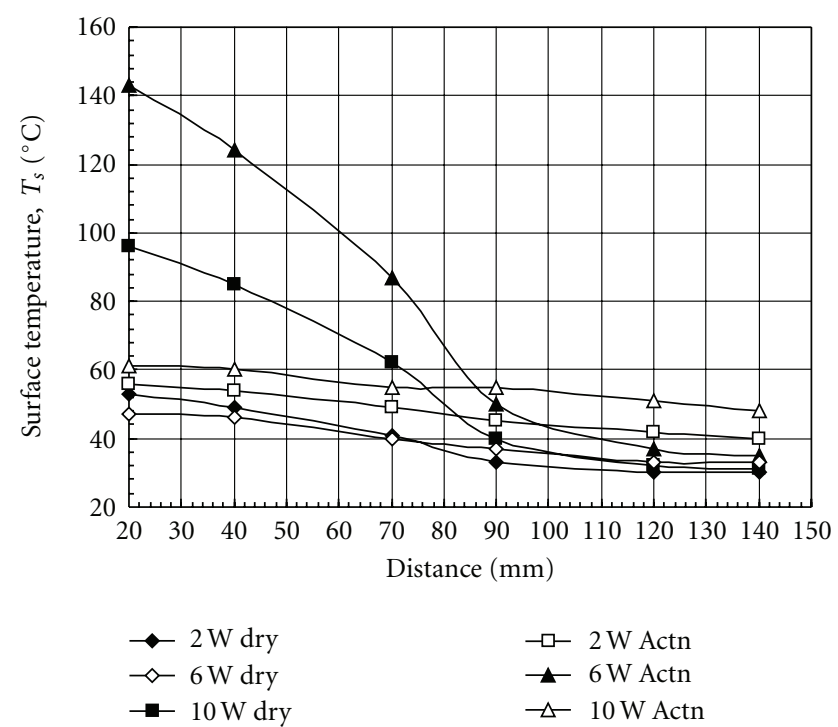

FIGURE 3: Comparison of surface temperature for dry run and with acetone (35\% fill ratio).

acetone $\left(T_{\text {sat }}\right.$ of acetone is $\left.56.5^{\circ} \mathrm{C}\right)$. For this reason, the acetone changes its phase (only the acetone changes its phase among the three liquids most of the time) and enhance the heat transfer due to which temperature drops and the axial gradient of surface temperature is smaller in the case of acetone.

In the case of methanol, the corresponding surface temperature is not so much suitable always for phase change, and thus the slope is relatively higher than acetone. For water, the corresponding surface temperature never reaches the boiling temperature of water which results in higher axial

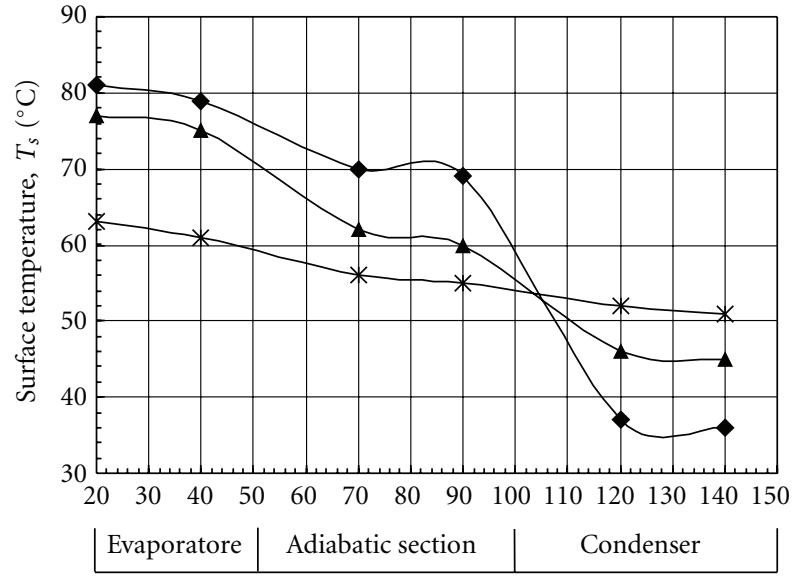

Distance (mm)

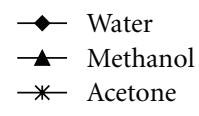

FIGURE 4: Surface temperature for different liquids (85\% fill ratio, $10 \mathrm{~W})$.

temperature gradient also. In condenser section, all the three liquids' corresponding surface temperatures are below their boiling temperature. Therefore, there is no chance here for phase change by any liquid. Here, water extracts more heat and drops down the surface temperature. In the single phase heat transfer (at condenser section) for the condition as described in the Figure 4, heat transfer is mainly dominated by specific heat of liquid (the specific heat of water is 4.18 $\mathrm{kJ} / \mathrm{kg} \cdot \mathrm{K}$, and it is $2.88 \mathrm{~kJ} / \mathrm{kg} \cdot \mathrm{K}$ for methanol and $2.28 \mathrm{~kJ} / \mathrm{kg} \cdot \mathrm{K}$ for acetone. Therefore, naturally, water extracts more heat from the condenser surface which consequences a lower surface temperature for water as reflects in the Figure 4.

The effect of fill ratio on surface tempearture is presented in Figure 5. The figure shows the surface temperature at $70 \mathrm{~mm}$ position against four fill ratio; $35 \%, 55 \%, 85 \%$, and $100 \%$. For water, the surface temperature $T_{s}$ drops very faster with fill ratio, it indicates that water enhances heat transfer as working fluid with increase of fill ratio. Figure 5 reveals that optimum fill ratio of a heat pipe is around $85 \%$. At around $85 \%$ fill ratio, the surface temperature, $T_{s}$, is the minimum for all the liquids, which indicates that at $85 \%$ fill ratio, heat flux is the maximum. The variation of surface temperature with latent heat of vaporization of liquid has been shown in Figure 6. Acetone has the lowest latent heat of vaporization, then methanol is higher, and water has the highest, latent heat of vaporization. For higher surface temperature (or higher power input), acetone shows minimum surface temperature relative to methanol and water. But for lower power input, surface temperature decreases with increase of latent heat of vaporization (i.e. sequentially acetone, methanol, and water).

3.2. Variation of Heat Transfer Coefficient, $h$. It is important to know the variation of heat transfer coefficient, $h$, with the 


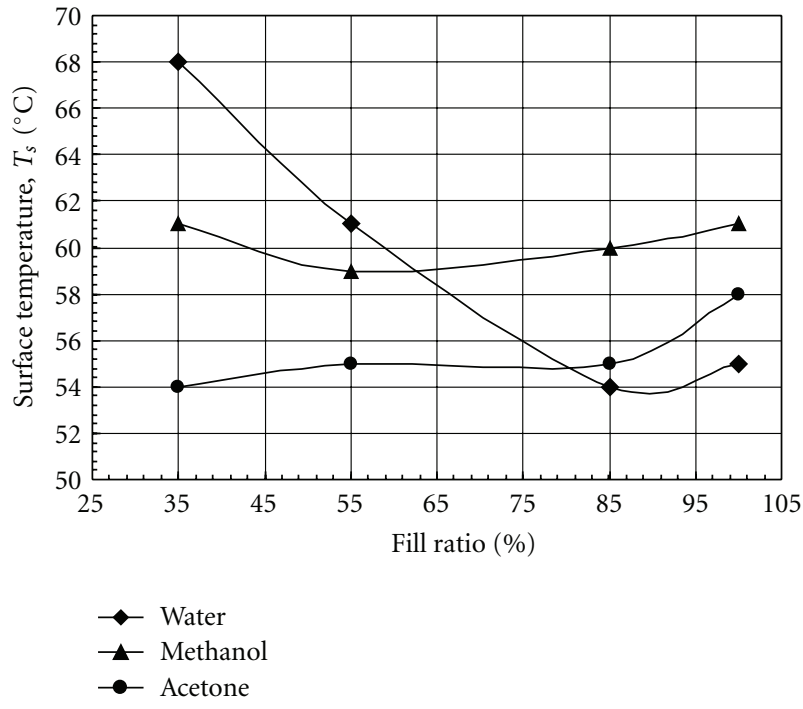

FIGURE 5: Surface temperature (at $70 \mathrm{~mm}$ position) with fill ratios $(8 \mathrm{~W})$.

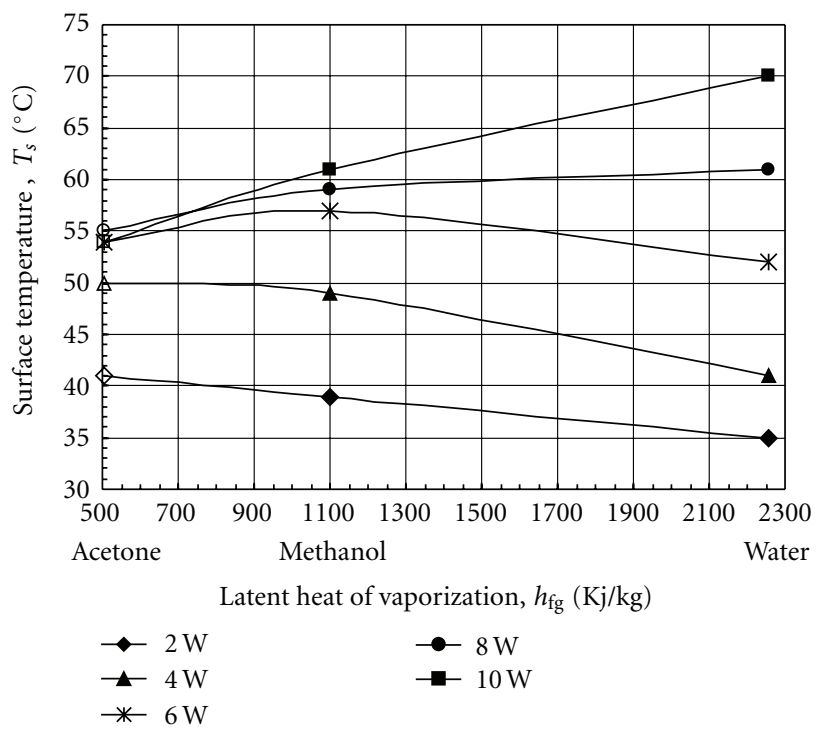

FIGURE 6: Effect of latent heat of vaporization on surface temperature (at position $70 \mathrm{~mm}$ ).

temperature difference $\left(T_{e}-T_{c}\right)$, which is the temperature difference between evaporator and condencser. Figure 7 shows the variation of $h$ with $\left(T_{e}-T_{c}\right)$ for dry run and three different liquids: water, methanol, and acetone with 35\% fill for each. For dry run, there is almost no change for $h$ with $\left(T_{e}-T_{c}\right)$; actually in the case of dry run only air participates (mainly by mode of convection) to carry the heat energy and with a bit of increase of temperature, there is no significant change of heat transfer mode from convection and ultimately no significant change on $h$. For all the liquids, $h$ increases with $T_{e}-T_{c}$; the rate of increase is very high for acetone with respect to other liquids. The rate of increase of $h$ with respect to $\left(T_{e}-T_{c}\right)$ is the highest for acetone, the second highest rate

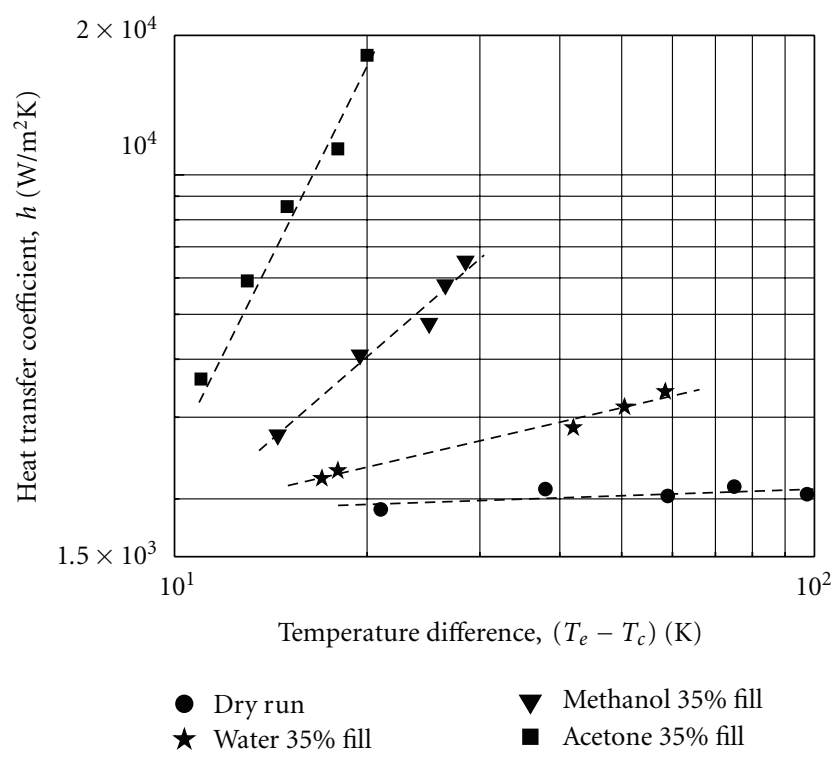

FIGURE 7: Heat transfer coefficient, $h$, with temperature Difference for different liquids.

is for methanol, the third highest is for water and the lowest rate is with dry run. The evaporator surface temperature is such that it is very much suitable for acetone to change its phase than other liquids. Maybe for this reason, acetone has the highest $h$ and methanol and water remain in the single phase and consequences lower $h$.

For the same reason as explained in the Figure 7, acetone shows the highest $h$ (among all the three) with the variation of fill ratio in Figure 8. The figure also shows that $h$ increases with fill ratio.

Saturated boiling temperature has a great effect on heat transfer coefficient, $h$, as shown in Figure 9. Heat transfer coefficients for two different experimental conditions $(6 \mathrm{w}$, $55 \%$ fill ratio and $10 \mathrm{w}, 55 \%$ fill ratio) are plotted against $T_{\text {sat }}$ here. The evaporator surface temperature, $T_{e}$, is also presented in the graph for corresponding $h$. It is revealed from the figure that for acetone and methanol the corresponding evaporator surface temperatures are more or less very close or above the corresponding saturated temperature of the liquid. In the case of water, the corresponding evaporator surface temperature is always below the saturated temperature of water. This means that there was no chance for water to phase change which consequences lower heat transfer coefficient for water.

3.3. Correlation for Heat Transfer Coefficient,h. From the discussions as presented in Sections 3.1 and 3.2, it is revealed that heat transfer is a strong function of evaporator temperature, $T_{e}$, liquid saturated temperature, $T_{\text {sat }}$, liquid latent heat vaporization, $h_{\mathrm{fg}}$, and fill ratio, $F$. On the basis of the dominating parameters of heat transfer coefficient $h$, a partially dimensionless correlation has been proposed in the present study. The dimensionless groups exist in the right side of the correlation as shown in (3). The left side's unit is Watt which is the unit of energy flow per unit time. In future 


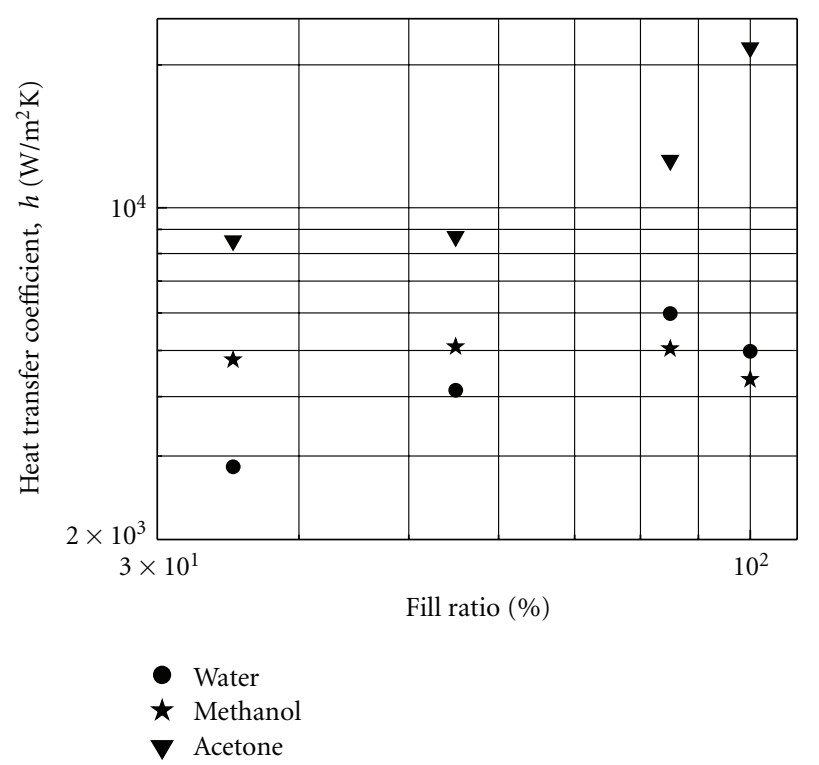

Figure 8: Heat transfer coefficient with fill ratio for different liquids $(6 \mathrm{~W})$.

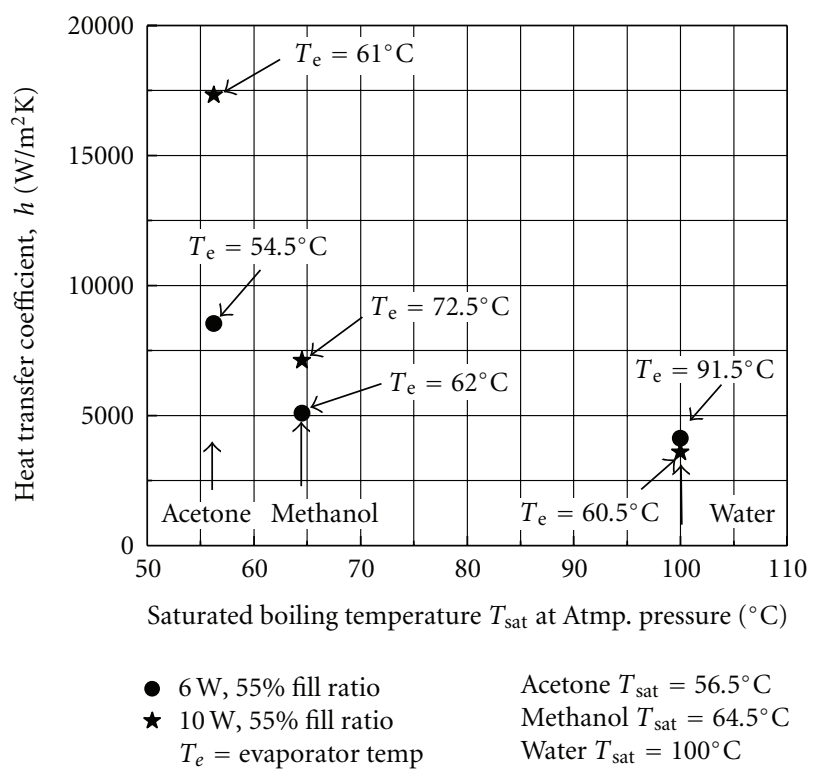

Figure 9: Heat transfer coefficient with saturated boiling temperature.

study, it will be tried to make the correlation completely dimensionless.

$$
h A\left(T_{\text {sat }}-T_{\mathrm{e}}\right)=39(\mathrm{Ja})^{4 / 5} \mathrm{~F}^{1 / 4}\left(\frac{\mathrm{T}_{\mathrm{sat}}}{\mathrm{T}_{\mathrm{e}}}\right)^{5} .
$$

Here,

$$
\mathrm{Ja}=\frac{C_{\mathrm{pl}}\left(T_{e}-T_{\mathrm{sat}}\right)}{h_{\mathrm{fg}}} .
$$

A dimensionless number, Ja Jackob number has been incorporated in the correlation. Ja plays a dominating role

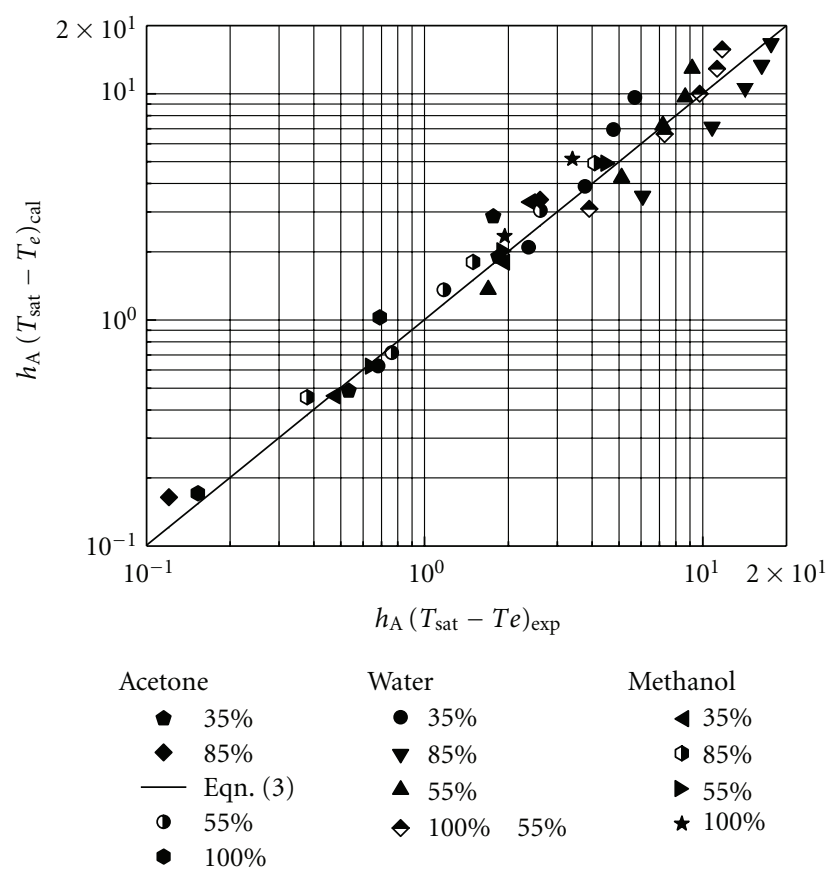

Figure 10: Correlation for heat transfer coefficient.

specially where phase change heat transfer occurs. Ja is a ratio of latent heat to sensible heat. The verification of the experimental data with the proposed correlation is shown in Figure 10.

Total twelve experimental conditions (three liquids with four fill ratios for each liquid) have been verified with the correlation and presented it in Figure 10. A fair agreement has been found here. Heat transfer coefficient can be estimated directly from the correlation.

\section{Conclusions}

Change of phase of working fluid during heating make the characteristics of heat transfer in the heat pipe more complicated. At the moment, the following conclusions can be drawn from the present study.

(i) The operating temperature of the evaporator of a heat pipe should be such that the evaporation of the working fluid can occur in it and in the condenser; the condensation occurs in it. This is important, because, without phase change, heat pipe cannot be used as an effective device for enhancement of heat transfer.

(ii) At $85 \%$ fill ratio, heat transfer is the maximum remaining other experimental conditions constant. For this reason, $85 \%$ fill ratio can be regarded as an optimum fill ratio.

(iii) The study reveals that the dominating parameters for the heat transfer of a heat pipe are saturated boiling temperature of the liquid, evaporator surface temperature, latent heat of vaporization of the working fluids, and fill ratio. 
(iv) A new correlation for the heat transfer coefficient has been proposed in the present study which fairly agrees with the experimental data.

\section{Nomenclature}

$T_{e}:$ average evaporator temperature $\left({ }^{\circ} \mathrm{C}\right)$

$T_{c}$ : average condenser temperature $\left({ }^{\circ} \mathrm{C}\right)$

$h$ : overall heat transfer coefficient $\left(\mathrm{W} / \mathrm{m}^{2} \cdot{ }^{0} \mathrm{C}\right)$

Q: heat input (W)

$A$ : heat transfer surface area at the evaporator $\left(\mathrm{m}^{2}\right)$

$T_{\text {sat }}$ : saturated temperature of liquid $\left({ }^{\circ} \mathrm{C}\right)$

Ja: Jackob number (-)

$F: \quad$ fill ratio $(-)$

$C_{p l}:$ specific heat of liquid $(\mathrm{kJ} / \mathrm{kg} \cdot \mathrm{K})$

$h_{f g}$ : latent heat of vaporization $(\mathrm{kJ} / \mathrm{kg})$.

\section{Acknowledgments}

The authors acknowledge their gratitude to the Department of Mechanical Engineering, Bangladesh University of Engineering and Technology (BUET) for providing necessary financial aid and other facilities to conduct the research. The authors also express their thankfulness to the personnel of different shops and laboratories for their help during the fabrication of the experimental setup.

\section{References}

[1] Y. F. Maydanik, "Review loop heat pipes," Applied Thermal Engineering, vol. 25, no. 5-6, pp. 635-657, 2005.

[2] T. Kaya, R. Pérez, C. Gregori, and A. Torres, "Numerical simulation of transient operation of loop heat pipes," Applied Thermal Engineering, vol. 28, no. 8-9, pp. 967-974, 2008.

[3] Y. Cao and M. Gao, "Wickless network heat pipes for high heat flux spreading applications," International Journal of Heat and Mass Transfer, vol. 45, no. 12, pp. 2539-2547, 2002.

[4] B. S. Larkin, "An experimental study of the temperature profiles and heat transfer coefficients in a heat pipe for a heat exchanger," Journal of Heat Recovery Systems, vol. 1, no. 4, pp. 315-325, 1981.

[5] B. Horbaniuc, A. Popescu, and G. Dumitraşcu, "The correlation between the number of fins and the discharge time for a finned heat pipe latent heat storage system," Renewable Energy, vol. 9, no. 1-4, pp. 605-608, 1996.

[6] L. Bai, G. Lin, H. Zhang, and D. Wen, "Mathematical modeling of steady-state operation of a loop heat pipe," Applied Thermal Engineering, vol. 29, no. 13, pp. 2643-2654, 2009.

[7] Y. Chen, M. Groll, R. Mertz, Y. F. Maydanik, and S. V. Vershinin, "Steady-state and transient performance of a miniature loop heat pipe," International Journal of Thermal Sciences, vol. 45, no. 11, pp. 1084-1090, 2006.

[8] Y. Tang, J. Xiang, Z. Wan, W. Zhou, and L. Wu, "A novel miniaturized loop heat pipe," Applied Thermal Engineering, vol. 30, no. 10, pp. 1152-1158, 2010.

[9] J. Li, D. Wang, and G. P. Peterson, "Experimental studies on a high performance compact loop heat pipe with a square flat evaporator," Applied Thermal Engineering, vol. 30, no. 6-7, pp. 741-752, 2010.
[10] Y. Lee and A. Bedrossian, "The characteristics of heat exchangers using heat pipes or thermosyphons," International Journal of Heat and Mass Transfer, vol. 21, no. 2, pp. 221-229, 1978.

[11] Z. J. Zuo and F. S. Gunnerson, "Heat transfer analysis of an inclined two-phase closed thermosyphon," Journal of Heat Transfer, vol. 117, no. 4, pp. 1073-1075, 1995.

[12] F. Garcia, J. Segura, and S. Zarea, "Thermal fluid dynamic steady state behavior of micro heat pipes," Universidad, Ciencia y Tecnologia, vol. 4, no. 14, pp. 59-66, 2000.

[13] H. B. Ma and G. P. Peterson, "The minimum meniscus radius and capillary heat transport limit in micro heat pipes," Journal of Heat Transfer, vol. 120, no. 1, pp. 227-233, 1998.

[14] G. P. Peterson and H. B. Ma, "Temperature response of heat transport in a micro heat pipe," Journal of Heat Transfer, vol. 121, no. 2, pp. 438-445, 1999. 

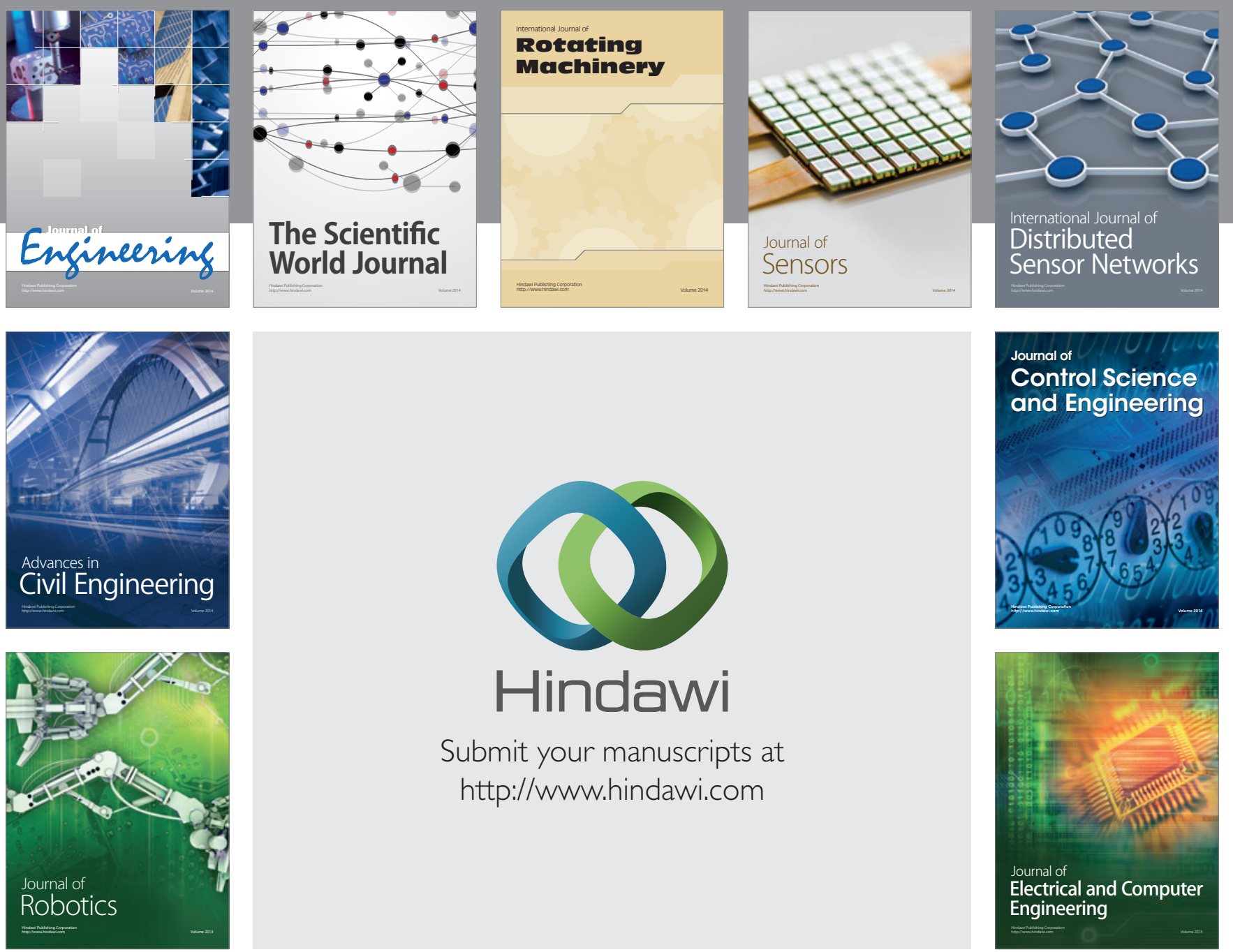

Submit your manuscripts at

http://www.hindawi.com
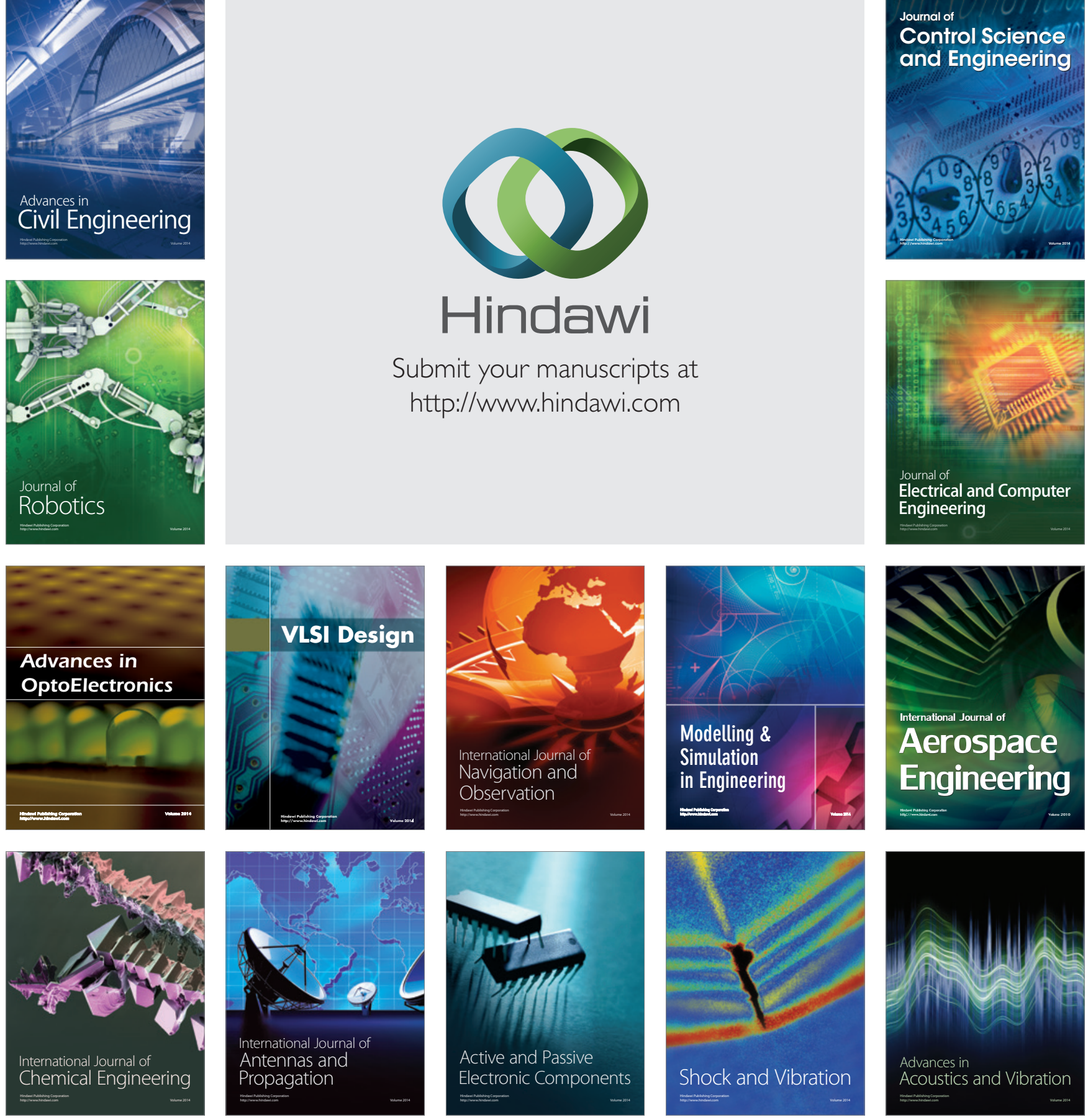